\title{
Municipal Waste Disposal on Soil Quality. A Review
}

\section{Sisay Taddese*}

Arsi University College of Agriculture and Environmental Science, Soil Resource and Watershed Management Department, Ethiopia *Corresponding Author: Sisay Taddese, Arsi University College of Agriculture and Environmental Science, Soil Resource and Watershed Management Department, Ethiopia.

Received: October 01, 2019; Published: November 05, 2019

DOI: 10.31080/ASAG.2019.03.0713

\begin{abstract}
Urban settler and diverse organization harvest a great amount of trashes in abundant forms, frequently making our environments dirty and unfriendly. The metropolitan discarded solid and liquefied waste disposal deteriorating soil quality through decrease in quality indicators because of the undiscriminating dumping of different waste. The movement of contaminated waste and mixed fluid away from the waste disposal borders presents serious environmental concerns of soil pollution. Thus, the focus of this review was to review city waste discarding effects on soil excellence at open leftover dumping places. In order to ascertain the quality of soil for public expenditure, recreation and irrigation purpose soil quality index was performed in indicating the soil quality. Agreeing to Different scholars, it was concluded that the average values of soil from municipal urban waste disposal in the world were found that all soil quality indicators was contaminated at the solid waste dumped site in comparison with the control sampling according to world standard for soil. But, the junkyards were actually observed to have large masses of totally decomposed organic materials on the soil. The nutrient balance would progress as organic matter level escalations and through it, yield potential. Enhanced soil structure also raises air pore space and aids soils resist compaction which decreases soil productivity and yields, limiting water penetration, air movement in the soil and root growth. Hence, management were required to undermine the cause of waste and treating the wasted with incineration and biological action.
\end{abstract}

Keywords: Municipal Solid Waste; Soil Quality

\section{Introduction}

Intensive industrial activities, inadequate urban waste disposal, mining, military activities or accidents had introduced excessive amounts of local soil and water contaminants. Soils only had a limited ability to process these contaminants, through filtering or transformation. Once this ability is exceeded, issues such as water pollution, human contact with polluted soil, plants taking up contaminants and dangers from landfill gases become more significant [1]. Areas with largest population generation had more waste than areas with low population. The generation is basically dependent on the socio-economic status and the nature of the activities of the people. The waste contribute to different environmental implications such as land pollution, which changes the aesthetic view of the environment, bad odor production, air pollution and underground water pollution [2].

The global population is expected to exceed nine billion people by 2050 . Major growth will take place in developing countries, particularly in urban areas that already have inadequate wastewater infrastructure. The economic, ecological and social costs were projected to escalation intensely if wastewater supervision receives urgent attention. Contaminated water from inadequate wastewater management provides one the greatest health challenges restricting development and increasing poverty through costs to health care and lost labour productivity. International, nearly 900 million individuals still do not have get to harmless water and certain 2.6 billion, al-most half the people of the developing world do not had access to adequate hygiene. At least 1.8 million kids less than five years old expire each year due to water related disease, accounting for around 17 percent of deaths in this age group. Worldwide some 2.2 million people die each year from diarrheal disease. Poor hygiene and unsafe water is responsible for around 88 percent of all diarrheal incidents [3].

Municipal Solid waste Management services in most of the countries come as a third priority in municipal commitments, after water supply and sanitation. The main environmental problem associated with the disposal sites was the potential risk posed to the soil. Since the waste was disposed directly onto surface of soil, a number of contaminants including heavy metals readily penetrate and eventually they contaminate the soil and affect vegetation abundance [4]. Depending on the propensity of the pollutants they initiate either in water held in the soil or percolated to the underground water. Noxious waste like $\mathrm{Cd}, \mathrm{Cu}, \mathrm{Ni}, \mathrm{Pb}$ and $\mathrm{Zn}$ can change the soil chemistry and had an influence on the animals and floras contingent on the soil for nutrition [5].

Human activity introduces heavy metals (such as cadmium, arsenic and mercury) to our soils through mining, smelting, industry, agriculture and burning fossil fuels. Our disposal of materials con- 
taining heavy metals - a long list which includes paint, electronic waste, and sewage, also contributes to the burden of heavy metal contamination. Soil contaminants may be responsible for health effects for millions of people. Health problems from cancers (arsenic, asbestos, dioxins), to neurological damage and lower IQ (lead, arsenic), kidney disease (lead, mercury, cadmium), and skeletal and bone diseases (lead, fluoride, cadmium) were serious issues (Bristol, 2013).

The level of physico-chemical parameters in groundwater around Olusosun dumpsite was observed to be higher than the corresponding groundwater around Solus area. Age of Olusosun dumpsite, nature and volume of solid waste deposited as well as the percentage of clay content in the soil from the sampling area could be certain influences accountable for the observation. All groundwater samples analyzed in the area are acidic in nature. This might be as results of high population density and industrialization in the area, consequently, the high level of $\mathrm{CO}_{2}$ in the atmosphere can result in acidic nature of water that percolates into aquifer. Very low $\mathrm{pH}$ in water is a form of health treats to human. Water quality index (WQI) further revealed that the impact of the dumpsites is still minimal in groundwater around Solus dumpsite compared to Olusosun dumpsite. WQI delineate water samples around Solus dumpsite as excellent - good - poor and that of Olusosun dumpsite as good - poor -very poor. Nearly all the groundwater composed round Olusosun dumpsite presented level of nitrate higher than that WHO allowable limit of $10 \mathrm{mg} / \mathrm{L}$. This condition is of great health danger as nitrate contamination has been linked to mirth and sometimes death [6].

Diversity of vegetation was directly influenced by soil characteristics. Many studies show evidence of seriousness of threats initiated by exposed waste removal finally affecting the plant life on the planet leading towards an irreversible erosion trend unless the present land use pattern is checked [7]. Hard leftover pollutants aid as an exterior force disturbing the physico-chemical features of soil ultimately causal towards the reduced production of flora [8]. The pollutants, in the first place, hinder the normal metabolism of plants which was an invisible injury and owing to which the visible injury appears in the aftermath [9].

The resident's progress has put incredible pressure on the excellence of Milieu of town life. The inhabitants produce various kinds of litters of biodegradable and non-biodegradable groups. The influence twisted by these wastes on the atmosphere is enormous, if appropriate discarding and management possibilities were not applied. The waste might become a resource and the people can advantage from these trashes with accurate collection and removal technologies. Majority of litters can be reprocessed and the recycling technologies accessible today global have a promising employ and energy producing options. The hygienic landfills, biogas making technologies, vermi- composting, incineration, municipal solid waste combustion technologies offer good motivations for the local bodies and the administrations to originate welfares by using the wastes [10].
Direct use of domestic wastewater (untreated wastewater) may not be healthy for agricultural purposes expect it undergoes certain wastewater treatment process. Poor quality water may affect irrigated crops by causing accretion of salts in the root zone, thus affecting the permeability/uptake of water from the topsoil to the vegetation. Contaminants in irrigation water when it accumulates overtime in an agricultural soils renders such soils unfit because of the accumulation of salts and other heavy metals present in the soil; thus reducing arable crop farming in agricultural activities [11].

It was depriving our ecosystem of the natural balance and bear result beyond any repair. Valuation of soil contamination becomes problematic when pollutants belong to dissimilar sources and their yields were variably disseminated [12]. Urban wastes dumping were resource materials which could help to progress soil arrangement and properties wanted in farming. The difficult of town waste managing which had been quite challenging could be translated into a valuable resource which would aid in assembly a portion of fertilizer necessities [13]. The effect gained displays that domestic solid waste with 90 percent is the dominant type of waste generated, which consist of bio-degradable and non-bio-degradable materials e.g. bottles, metal rags, leaves etc. The lowest type of waste generated was commercial with 10 percent [2]. The Urban Hard Leftover discarding site for the town of India had become an overflowing landfill due to the undiscriminating removal of solid waste at the site [14]. The hard leftover couriers highly expanded nature at physicochemical and biological features which was extremely influenced by socioeconomic localities [15]. Hence the objective of this review was to revise urban waste disposal effects on soil and water quality at open waste dumping sites.

\section{Concept of urban waste disposal}

Municipal solid waste (MSW) is a leftover from houses and other waste that was alike to discard from households [16]. Similarly, Solid waste was utilized to pronounce non-liquid waste material arising from local, trade, commercial and public services. It comprises of countless different materials. Powder, Nutrition litters, packing in form of paper, metal, plastics or glass, rejected dress, garden wastes, compulsive waste, dangerous leftover and radioactive waste [17]. Waste management facilities were poorly designed, private waste collection firms were absent, lack of participation and cooperation apart from the inhabitants which were necessary ingredients of good government, had greatly hampered the success of waste management. All these put together and result to proper inefficiency of solid waste management and effect of growing waste could daily be seen in various communities as a whole [2]. The biophysicochemical value of diverse types of water foundations used by community for human ingesting had consequence in providing baseline water quality data. Moreover, it donated to recognize the chief concerns regarding the quality of drinking water conferring to world health organization $[18,19]$. 


\section{Urban waste disposal effects on soil contamination}

Nowadays, composted municipal solid waste (MSW) was being general in cultivation as a soil conditioner and fertilizer. MSW reprocessing for agrarian use in system of composting was obviously a better way of MSW removal than e.g. landfilling, which was linked with some vital financial and ecological issues, such as cost for landfilling; legislation to protect environment; use of chemical fertilizers, and ability for house waste reusing [16]. Two different types of soil contamination to consider were local soil contamination (the result of intensive industrial activities or waste disposal) and diffuse soil contamination covering large areas. Pollution by heavy metals and organic contaminants is probably the most serious problem as the contamination was practically irreversible. Contamination could affect human health either through direct contact or by ingestion through the food chain (Bristol, 2013). Contamination can seriously affect soil's ability to perform some of its key functions in the ecosystem. Soil is a living resource, but once contamination exceeds a certain threshold, the soil may be considered utility lifeless. Pollution by heavy metals and many organic contaminants is practically irreversible [1].

The physicochemical and microbiological investigation of discarded solid leftover at field land places showed partial impulsive to nearly bio manure due to extended period span of accretion, the sludge examples of both the field terrestrial sites consist relatively higher bacteriological inhabitants and wide diversified microbial public with wide nutritive catabolic profile [20].

Health problems due to toxic heavy metals is Extended period exposure to cadmium is allied with renal dysfunction. Cadmium is bio persistent and once engrossed remains resident for numerous years. Cadmium may also cause bone defects in humans and animals. Low exposure to chromium can irritate the skin and foundation of ulceration. Elongated term experience can cause kidney and liver damage. It can also source harm to cardiac and nerve tissues. Aluminum poisonousness is related with the growth of bone disorders. Acquaintance to high levels of arsenic cans basis death. All types of arsenic contact can origin kidney and liver injury and in the greatest severe introduction there is erythrocyte hemolysis. Great quantities of copper can source anemia, liver and kidney harm, and stomach and intestinal irritation. Excessive quantities of nickel can be mildly toxic. Extended term contact can reasons reduced body weight, heart and liver harm and skin annoyance. Manganese is recognized to chunk calcium channels. This reproductions nearly all of the symptomology of Parkinson's disease [21].

\section{Urban waste disposal effect on physical properties soil}

The wide spread litters and heaps of solid waste occupied a very huge area of land in Nigerian Air Force Base. Owing to attributed to the high influx of population and urbanization, so much value of solid waste generating daily and were inefficiently managed. These outstretched the existence of waste disposal facilities and consequently led to the indiscriminate waste accumulation along roadside, gutters, drainage, open spaces, hence causes a lot of nuisance to environment and destruction of lives and properties. Domestic waste constitutes the largest proportion of the waste generated which is earlier biodegradable or non-biodegradable materials [2]. The usage of composted organic wastes yields alterations in soil physical, chemical and biological belongings and could enhance plant growth after its application. However, the influence of $\mathrm{C}$ rich materials, like municipal organic wastes compost, on soil physical, chemical and biological properties be contingent upon numerous influences: amount and mechanisms of additional organic resources, soil type and climate conditions [22].

\section{Bulk density and soil moisture content}

There was a high coefficient of alienation in bulk density among junkyard and non-dump sites. The rubbish dump site soils had 9-13\% fewer bulk density in their first and second horizons, while only minor differences in bulk density were observed in the third horizon. This displays that the outcome of the dumping on bulk density lessened with soil depth. Differences in bulk density between dump and non-dump sites may be because organic and inorganic materials in the municipal wastes help to increase the soil matrix thereby reducing soil bulk density [23]. Amid all the soils considered the non-dumpsite recorded the uppermost bulk density and lowest total porosity and moisture content. This displayed that the non-dumpsite had a very low ability to retain water. Thus, authorizing the detail that biodegradable leftover when applied to the soil improves the capability of the soil to hold water [24]. Soil physical properties, in a parallel method to chemicals, were also better after urban waste disposal accumulation. Metropolitan waste removal application inclined to decrease BD. The reduction in BD looks to have been owing to watering of the denser mineral portion by the less dense municipal waste disposal doses Gabriela [25].

Moreover, Karl (2004) obtained that, in the upper soil, biological activity can act to reduce soil BD while at lower depths soil texture and gravel content may increase soil BD. The thought made in this effort was also in contract with the work complete by in which they reported higher weighty metals attentiveness in dumpsites than a non-dumpsite. Soil moisture and water penetration were knowingly affected by municipal solid waste compost additions. Intermediate and great compost doses ( 4 and $7 \mathrm{~kg} \mathrm{~m}-2$, respectively) displayed the maximum soil moisture and water penetration rates associated to control and $2 \mathrm{~kg} \mathrm{~m}-2$. An escalation of water infiltration and wetness should be considered as a result of total porosity increase in soils after municipal hard leftover manure composts application [25].

\section{Soil texture}

The soils of the nominated dump sites were mainly sandy loam in the first and second horizons, while the third horizon was conquered by sandy clay loam to clayey texture. In dissimilarity, the soils of the non-dump sites were mainly sandy clay to clayey soils. The results show that the sand fraction of the soil decreased slightly with increased soil depth [23]. Entirely soil examples at the numerous horizons in all locations were sandy loam in texture. The top soil at the rubbish dump sites had been changed by the occurrence of the solid discarded at the site. Soil samples collected at horizons $0-15$ and 30-45 of the dumpsites and controls 
were extremely sandy in nature with the mixture of silt and clay in which the texture class was sandy loam. The nutrient equilibrium will advance as organic matter level escalations and with it. Betterquality soil assembly also upsurges air pore space and aids soils struggle compaction which lessens soil productivity and yields, limiting water permeation, air drive in the soil and root growth. A high cation exchange capacity increases soil fertility and resilience. It also helps soil aggregation which reduces the chance of soil erosion and crusting. The presence of the dump has thus improved the soil structure and efficacy in agricultural activities in the three locations [13].

\section{Urban waste effect on chemical properties soil}

\section{Macro minerals}

As with plant uptake, soil $\mathrm{pH}$, organic matter content, and other soil characteristics affect the amount of leaching. Cadmium, lead and mercury can be harmful to animals and humans at relatively low concentrations and thus should receive close scrutiny in relation to application of municipal solid waste composts to agricultural soil. The deposition of industrial waste, mining activities, incidental accumulations, atmospheric deposition, and agricultural chemicals are some sources for the pollution of soils with heavy metals [6]. The pH reduced from 6.94-6.03 at the $0-15 \mathrm{~cm}$ horizon representative that the occurrence of the junkyard amplified acidity of the soil. Additional serious parameters in agriculture that were raised by the attendance of the garbage dump in the $0-15 \mathrm{~cm}$ horizon include organic $\mathrm{C}$, organic matter, total nitrogen, $\mathrm{Ca}, \mathrm{Mg}$, $\mathrm{K}, \mathrm{Na}$, giving rise to a percentage base saturation. The entire phosphorus content of the soil in the three places and their controls did not display any constancy in difference at the three horizons while there was a decrease in total P (from 12 to $10 \mathrm{mg} / \mathrm{kg}$ ) at the $0-15 \mathrm{~cm}$ level and upsurge $(8-30 \mathrm{mg} / \mathrm{kg})$ at the $15-30 \mathrm{~cm}$ and $16-40 \mathrm{mg} / \mathrm{kg}$ at the $30-45 \mathrm{~cm}$ levels. Similarly, the junkyards were physically perceived to have great masses of entirely decayed organic materials on the soil. Organic matter improves soil structure and upsurges the soil's capability to hold water [13]. Sulphate in soil did not display any difference. The concentration of ammonia was very great in the control soil as associated to the contaminated soil. There was not much change in nitrate concentration. Below anaerobic situations the nitrates in the soil reduces when the microbes use up the oxygen existing with nitrates. Here as the reaction fashionable was aerobic; there was no decrease in nitrate concentration. Over again lack of oxygen avoids nitrification and denitrification and due to this the ammonia concentration was not affected by the reactions in soil [14].

Organic matter levels were very high in the rubbish dump sites related to the non-dump sites. The organic matter of $16.5 \%, 15.3 \%$ and $22.0 \%$ were noted for the upper layer of soils at junkyard sites I, II and III places, respectively. These represent increases in organic matter of 701-743\%, respectively, when compared to the nondump sites. The soil organic matter content sharply declined by an average of $731 \%$ in the second and third horizons of the dump site soil. In contrast, the level of organic matter in the upper horizon of the non-dump sites weakened in the second and third layers relative to the first by an average of $73 \%$. The $\mathrm{N}$ content of the soils was high at different dump sites when associated to the non-dump places. The percent $\mathrm{N}$ content of $0.85 \%, 0.76 \%$ and $0.97 \%$ at the upper horizon of sites I, II and III site, respectively. These represent increases in N content of 750\%, 660\% and 646\% for sites I, II and III, respectively. The $\mathrm{N}$ content decreased with increase in profile depth by an average of $732 \%$ in the second and third horizons of the dump sites [23].

The usage of natural wastes in agriculture theaters excessive role in reprocessing essential plant nutrients, supporting soil safety as well as defensive the atmosphere from unwelcome dangers. Urban solid leftover is mainly used as a foundation of nitrogen and organic matter, refining soil goods and microbial action that are closely associated to soil fertility. Biological leftover and food discarded rise $\mathrm{pH}$, nitrogen gratified, cation exchange capacity, water holding capacity, and microbial biomass in soil. Manure sludge contains many amounts of organic matter and huge quantities of plant nutrients. Compost is a mutual waste which recovers soil properties by addition nutrients and increases microbial and enzyme activity in soil. It also decreases toxicity of certain heavy metals. These biological wastes have excessive affirmative effect on soil physical, chemical, and biological properties as well as rouse plant growth and thus surge the yield of crops [26]. The physicochemical examination of hotels, fruit market and vegetable marketplace trash samples represent suitable value of $\mathrm{C} / \mathrm{N}$ ratio, qualifying them as appropriate material for composting as well as the higher measurable content of organic carbon and nitrogen value and its combination into solid discarded complex might show a important role in potent sustainable composting process [20].

\section{Micro minerals}

Heavy metals ( $\mathrm{Pb}, \mathrm{Cu}, \mathrm{Fe}$ and $\mathrm{Zn}$ ) levels were increased at the municipal waste dump sites relative to the non-dump sites. The investigation of the heavy metal content of these sites was restricted to the upper $(15 \mathrm{~cm})$ soil horizon. Soil $\mathrm{Pb}$ levels in the dump site soils (68.2, 72.1 and $63.4 \mathrm{mg} \mathrm{kg} 1$ for sites I, II and III, respectively) increased by approximately $214-294 \%$ in the three dump sites relative to the non-dump sites. The increase in $\mathrm{Pb}, \mathrm{Fe}, \mathrm{Cu}$ and Zn content in the dump sites relative to the non-dump sites must be attributable to dumping of municipal wastes on the various dump sites. Increased heavy metal content of the soil can lead to increased plant uptake of metals that may be injurious to human and animal health [23]. The composting of animate litters is the most mutual knowledge of reprocessing and disposing them easily in a nontoxic way. The animate trashes can advance soil physical and chemical properties, surge soil biological movement, and withstand soil health. Animate wastes upsurge the OM content of soil, thus its water holding capacity, porosity, infiltration capacity, hydraulic conductivity, and water stable combination and decrease bulk density and surface crusting. They also deliver vital plant nutrients and preserve soil richness and thus arouse crop growth and yield. By increasing microbial action, the animal manures enhance enzyme actions, microbial breathing and thus upsurge nutrient obtainability for agricultural crops. Moreover, they also reduce toxicity of some heavy metals such as $\mathrm{Cd}$ and $\mathrm{Cr}$. It may be decided that organic wastes from different sources can be used for improving 
soil health (properties) and stimulating plant growth and yield. In addition, $\mathrm{Na}+$ release exacerbates soil salinity; occasionally harmful heavy metals may be released [26].

The positioning animal waste on agricultural land advances soil physical and chemical properties. Better soil properties help to boost the soil fertility level, soil productivity, and soil organisms which provide cementing polysaccharides that act as binding agents for mineral particles, thus, enhancing aggregation and refining soil structure for easy root penetration which in turn simplifies plant growth. The dumpsite wastes increased $\mathrm{Pb}, \mathrm{Cu}, \mathrm{Cd}, \mathrm{SO}_{4}^{2-}$, $\mathrm{NO}_{3}-$ and $\mathrm{NH}_{4}+$ of the soils to non-hazardous levels as their values lie within acceptable levels in soils [24]. Heavyweight metals are kept beneath ecological contaminant group due to their toxic belongings on plants, fauna and human being. Heavy metal pollution of soil results from anthropogenic as well as natural activities. Anthropogenic actions such as mining, smelting process and agriculture have locally augmented the levels of heavy metals such as $\mathrm{Cd}$, $\mathrm{Co}, \mathrm{Cr}, \mathrm{Pd}$, As and $\mathrm{Ni}$ in soil up to hazardous levels. Heavy metals are tenacious in natural surroundings, therefore get accrued in soils and plants. Dietary intake of many heavy metals through consumption of plants has long term detrimental effects on human health. The impact of the heavy metals on aquatic organisms is due to the movements of pollutants from various diffuse or point sources which gives rise to coincidental mixtures in the ecosystem. Among the contaminants pesticides, heavy metals, and cleaners are the major cause of anxiety for aquatic situation because of their toxicity, persistency and tendency to accrue in organisms. Among the 19 heavy metals lead, cadmium, and mercury do not have any biological significance or beneficial use and known to be extremely toxic. Additional metals are chromium, copper, manganese nickel, tin and zinc once detached in the biosphere these metals cannot be improved or degraded. Hence ecological belongings of metal contamination are said to be enduring. Metal pollution has harmful effect on biological systems and does not undergo biodegradation. Toxic heavy metals such as $\mathrm{Pb}, \mathrm{Co}, \mathrm{Cd}$ and $\mathrm{Hg}$ can be differentiated from other pollutants, since they cannot be biodegraded but can be accrued in living organisms, thus producing various diseases and disorders even in relatively lower concentrations [21].

Elevated values of $\mathrm{Pb}, \mathrm{Cd}$, and $\mathrm{Cr}$ were found in soils at the refuse dumps when compared to control samples and established guidelines of several countries. No evidence of elevated values of Co in soils was found; but Ni was slightly elevated in some samples. It was found that $\mathrm{Pb}$ generally has the highest concentrations in the soil layers while $\mathrm{Cd}$ generally is least detected. The values of $\mathrm{Pb}$ were above the allowable limits for soils, in several countries. This raises significant concern for safety of the environment and health impacts on the populace and calls for urgent attention and appropriate response. Soil samples from some dump sites also exceeded the allowable limits in the cases of $\mathrm{Cr}$ and $\mathrm{Cd}$ (Adelekan and Alawode, 2011).

\section{Urban waste disposal on soil microorganism}

Heavyweight metals, with soil dwelling times of thousands of years, existing numerous health hazards to higher organisms [27].
They were similarly recognized to decrease plant growth, ground shelter and had a undesirable impact on soil micro flora [28]. Soil microbial biomass represents the fraction of the soil responsible for the energy and nutrient cycling and regulation of organic matter transformation. the organic residues were converted to biomass or mineralized to $\mathrm{CO}_{2}, \mathrm{H}_{2} \mathrm{O}$ and mineral nutrients representing an important pool of nutrients ( $\mathrm{N}, \mathrm{P}$ and $\mathrm{S}$ ), which were continually Assimilated during the growth of microorganisms. Thus, microbial biomass was considered important source and drain of nutrients in the soil, promoting mineralization of organic matter in inorganic nutrients $\left(\mathrm{NH}_{4}+, \mathrm{NO}_{3}, \mathrm{H}_{2} \mathrm{PO}_{4}, \mathrm{SO}_{4}{ }^{2}\right.$ and $\left.\mathrm{CO}_{2}\right)$ and consequent availability for plant growth, or immobilizing the nutrients in microbial tissues for their maintenance and growth [29].

\section{Cause of soil pollution}

Lead is used in the construction industry for proofing flashing and for sound proofing, used in pipes. Wellbeing belongings of lead is inhalation and ingestion, kidney and central nervous system, and interfers with the normal development of brain in infants, lower IQ levels in children. Cadmium is used as an electrode in nicad battries, a pigment in paints, Cigarette smoke, Fertilizers and pesticides. Is exposure to our food supply sea food organ meats, Kidneys and also fran potatoes, Rice and other grains. Health Effects of cadmium Great contact can lead to disruptive lunge illnesses and has been linked to lung cancer. In very high levels it possesses thoughtful health difficulties related to bone defects in humans and animals liver and Kidneys and can cause death. Food intake and tobacco smoking are the main routes by which Cadmium enters the body [21]. There was a alteration in the center of each dumpsite at interval of 10-70 $\mathrm{m}$ down the slope. The dumpsites were found to contain significant amount of toxic heavy metals. The attentions of heavy metals were got to be uppermost at the center of all dumpsite and vary meaningfully at a distance of $10 \mathrm{~m}$ away from the midpoint of these dumpsites to $70 \mathrm{~m}$ down slope. Though, leakage of heavy metals was originate to have taken residence but not to a distance as extended as $200 \mathrm{~m}$ from the last sampling argument on every dumpsite. The dumpsite also confined augmented absorptions of toxic heavy metals, which may reach toxic levels through the food chain [30-34].

\section{Conclusion}

The municipal urban solid waste or slurry waste discarded to the open waste dumping site that located in the nearly residential area which determined in terms of biological, physical and chemical indicators for soil quality measuring indicate series damage to soil through excess and lesser presence of chemical with regard to their standard. The garbage dumps were physically detected to have large masses of totally decomposed animate resources on the soil. The nutrient balance would progress as animal substance level upsurges and with it, yield potential. Better-quality soil arrangement also surges air pore interplanetary and aids soils counterattack compaction which decreases soil productivity and yields, limiting water penetration, air drive in the soil and root growth. The main ecological problem associated with the disposal sites is the potential risk posed to the soil. Since the waste was disposed 
directly onto surface of soil, a number of contaminants including heavy metals like $\mathrm{Pb}, \mathrm{Cd}, \mathrm{Cr}$, $\mathrm{Co}$ and $\mathrm{Ni}$ readily influences to the surface and eventually they contaminate the subsurface of the soil and affect microorganism abundance. So, it is recommended that, this open dump site should be closed and the municipal afford training to the community regarding pretreatment and use sustainable waste disposal system.

\section{Bibliography}

1. EEA. Progress in management of contaminated sites (CSI 015). Copenhagen: European Environment Agency (2007).

2. Abdullahi I., et al. "Environmental Impact of Indiscriminate Waste Disposal". International Journal of Engineering and Applied Sciences (IJEAS) 1.1 (2014).

3. Corcoran E., et al. "Sick Water? The central role of wastewater management in sustainable development". A Rapid Response Assessment. United Nations Environment Programme, UNHABITAT, GRID-Arendal (2010).

4. Syeda Maria Ali., et al. "Open dumping of municipal solid waste and its hazardous impacts on soil and vegetation diversity at waste dumping sites of Islamabad city". Journal of King Saud University-Science 26 (2014): 59-65.

5. Shaylor H., et al. "Sources and Impacts of contaminants in Soil". Cornell Waste Management Institute (2009).

6. Adeyi AA and Majolagbe AO. "Assessment of Groundwater Excellence around 2 Main Lively Dumpsites in Lagos, Nigeria". B Chemistry Volume 14 Issue 7 Version 1.0 Year 2014 Type: Double Blind Peer Reviewed International Research Journal Publisher: Global Journals Inc. (USA) (2014).

7. Phil-Eze PO. "Variability of soil properties related to vegetation cover in a tropical rainforest landscape". Journal of Geography and Regional Planning 3 (2010): 177-184.

8. Papageorgiou M. "Public community partnerships for waste collection in three Indian cities, an exercise in world making - best student essays of 2005-06". International Institute of Social Studies 24 (2006): 104-117.

9. Ahmed S., et al. "Effect of atmospheric pollution on chlorophyll and protein contents of some plants growing in Karachi region". Pakistan Journal of Scientific and Industrial Research 29 (1986): 154-170.

10. Upadhyay VP., et al. "Eco Tools for Urban Waste Management in India”. Journal of Human Ecology 18 (2005): 253-269

11. Musa jj., et al. "Quality Evaluation of Household Wastewater for Irrigation". JASEM 15 (2011) 431-437.

12. Partha V., et al. "Assessment of heavy metal contamination in soil around hazardous waste disposal sites in Hyderabad city (India): natural and anthropogenic implications". Journal of Environmental Management 2 (2011): 027-034.
13. Ubuoh EA., et al. "The Potentials of Solid Wastes Utilization for Agriculture in Imo State, Nigeria". International Journal of Multidisciplinary Sciences and Engineering 3 (2012): 45-45.

14. Sruti Pillai., et al. "Soil Contamination near a Urban Hard Leftover Removal Site in India". International Conference on Biological, Civil and Environmental Engineering (2014): 148-153.

15. Seema Jilani. "Urban hard leftover composting and its assessment for reuse in plant production". Pakistan Journal of Botany 39 (2007): 271-277.

16. Mbarki S., et al. "Conflicting effects of urban manure on alfalfa growth in clay and in sandy soils: N, P, K content and heavy metal toxicity". Bioresource Technology 99 (2008): 6745-6750.

17. Modak PR and Nangare PB. "Quantitative and Qualitative Assessment of Municipal Solid Waste For Nagpur City". Journal of Environmental Research and Studies 2.2 (2011): 55-61.

18. Sabrina Sorlini., et al. "Assessment of Physical-Chemical Drinking Water Quality in the Logone Valley (Chad-Cameroon)". Sustainability 5 (2013) 3060-3076.

19. Yirdaw Meride and Bamlaku Ayenew. "Drinking water quality assessment and its effects on residents health in Wondo genet campus, Ethiopia". Environment System Research 5 (2016).

20. Atalia KR., et al. "Microbial Biodiversity of Municipal Solid Waste of Ahmedabad". Journal of Materials and Environmental Science 6 (2015): 1914-1923.

21. Raja Rajeswari and Namburu sailaja. "Influence of Heavy Metals on Ecological Pollution. Nationwide Session on Influence of Toxic Metals, Minerals and Solvents leading to Environmental Pollution". Journal of Chemical and Pharmaceutical Sciences 3 (2014): 175.

22. Drozd J. "The risk and benefits associated with utilizing composts from municipal solid waste (MSW) in Agriculture". (2003): 211-226.

23. Anikwe MAN and Nwobodo KCA. "Extensive term effect of urban waste disposal on soil properties and productivity of sites used for urban agriculture in Abakaliki, Nigeria". Bioresource Technology 83 (2002) 241-250.

24. Njoku C. "Effect of Wastes on Selected Soil Properties in Abakaliki Southeastern Nigeria". International Journal of Plant and Soil Science 4 (2015): 94-99.

25. Gabriela Civeira. "Influence of municipal solid waste compost on soil properties and plant reestablishment in peri-urban environments". Chilean Journal of Agricultural Research 70 (2010): 446-453.

26. Hossain m.z., et al. "Effect of different organic wastes on soil properties and plant growth and yield: a review". Scientia agriculturae bohemica 48 (2017): 224-237. 
27. C Garbisu and I Alkorta. "Phytoextraction: A Cost- effective Plant-Based Technology for the Removal of Metals from the Environment". Bioresource Technology 77 (2001): 229-236.

28. McGrath FJ Zhao and E Lombi. "Plant and Rhizosphere Processes Involved in Phytoremediation of Metal Contaminated Soils". Plant and Soil 232 (2001): 207-214.

29. Gregorich EG., et al. "Towards a minimum data set to assess soil organic matter quality in agricultural soils". Canadian Journal of Soil Sciences 74 (1994): 367-385.

30. EE Awokunmi., et al. "Effect of leaching on heavy metals concentration of soil in some dumpsites". African Journal of Environmental Science and Technology 4 (2010): 495-499.

31. Minbale Aschale., et al. "Potentially Toxic Trace Element Contamination of the Little Akaki River of Addis Ababa, Ethiopia". Journal of Natural Sciences Research 5 (2015).

32. SAS institute. SAS User's Guide, Statistics Version 9.2 (Ed.).SAS Inst., Cary, NC, USA (2008).

33. Sharda AK and Sharma MP. "Water quality assessment of Swan River in Himachal Pradesh, India". Alternate Hydro Energy Centre, Indian Institute of Technology Roorkee, India 4.3 (2007).

34. Yohannes $\mathrm{H}$ and Elias E. "Contamination of Rivers and Water Reservoirs in and Around Addis Ababa City and Actions to Combat It". Environment Pollution and Climate Change (2017).

\section{Volume 3 Issue 12 December 2019}

(c) All rights are reserved by Sisay Taddese. 